\title{
Review
}

Pharmacology

Pharmacology 2015;95:111-116

DOI: $10.1159 / 000375503$
Received: November 3,2014

Accepted after revision: January 26, 2015

Published online: March 13, 2015

\section{Targeting DNA Methylation with Green Tea Catechins}

\author{
Eugenia C. Yiannakopoulou \\ Department of Medical Laboratories, Faculty of Health and Caring Professions, Technological Educational \\ Institute of Athens, Athens, Greece
}

\section{Key Words}

Green tea catechins - Epigallocatechin gallate - DNA methylation · DNA methyltransferase · Tumor suppressor gene activation

\begin{abstract}
Aberrant epigenetic alterations in the genome such as DNA methylation play a significant role in cancer development. Green tea catechins have been reported to modulate epigenetic processes. This review aims to synthesize evidence on the modulation of DNA methylation by green tea catechins. Green tea catechins have been reported to reverse DNA methylation of tumor suppressor genes and increase transcription of these genes. Green tea catechins and especially epigallocatechin gallate modulate DNA methylation by attenuating the effect of DNA methyltransferase 1 (DNMT1). However, the exact mechanism of DNMT1 inhibition is not delineated. Suggested mechanisms include direct enzymatic inhibition, indirect enzymatic inhibition, reduced DNMT1 expression and translation. The possible effect of green tea catechins on other pathways of DNA methylation, i.e. methyl-CpG binding domain proteins, has not been investigated. Furthermore, the link between redox properties and epigenetic modulation by green tea catechins has not been defined either. Since green tea catechins are natural compounds with a rather acceptable safety profile, further research on their action as inhibitors of DNA methylation seems worthwhile.
\end{abstract}

\section{Introduction}

Classical knowledge indicates that mutation or deletion of coding regions is responsible for gene inactivation. However, since the early 1990 s, a new molecular pathway of gene silencing has been discovered [1]. In this pathway, the DNA promoter hypermethylation is a key epigenetic mechanism for the silencing of many genes, including those for cell cycle regulation, receptors, DNA repair and apoptosis [2-4]. Hypermethylation of $\mathrm{CpG}$ islands may inhibit transcription by recruiting the methyl-CpG binding domain proteins or by interfering with the recruitment and function of basal transcription factors or transcriptional coactivators $[5,6]$. Silencing of the expression of gatekeeper or mismatch genes promotes growth in the affected cells. DNA methylation of tumor suppressor genes is thought to be an early event in carcinogenesis [7]. DNA methylation is modulated by DNA methyltransferases (DNMT) $[8,9]$. The human genome includes 4 genes that code DNMTs (DNMT1, DNMT2, DNMT3A and DNMT3B) with DNMT1 and DNMT3B being the more potent [8-10]. On the other hand, global DNA hypomethylation is associated with chromosomal instability and is an early event in the neoplastic progression of most human and animal cancers including colon cancer $[6,11]$.

Polyphenols, particularly flavonoids, constitute the most interesting component of green tea leaves. Catechins (flavan-3-ols) are the main flavonoids present in green tea. The four major catechins are: (-)-epigallocatechin-3-gallate (EGCG), which represents approximately $59 \%$ of the

\section{KARGER 125}

C 2015 S. Karger AG Basel

0031-7012/15/0954-0111\$39.50/0
Eugenia C. Yiannakopoulou Eleutheriou Benizelou 106 GR-17676 Athens (Greece) E-Mail nyiannak@teiath.gr 
total of catechins; (-)-epigallocatechin (EGC; approximately 19\%); (-)-epicatechin-3-gallate (ECG; approximately $13.6 \%$ ), and (-)-epicatechin (EC; approximately $6.4 \%)[12,13]$. The potential cancer chemopreventive and therapeutic properties of teas and tea polyphenols have been in the focus of research efforts in the last 2 decades. Recent data have shown strong chemopreventive and possibly cancer chemotherapeutic effects of green tea polyphenols and EGCG against cancers of the skin (UV radiation and chemically induced), lung, breast, colon, liver, stomach and prostate [14-19]. In vitro and in vivo data suggest that green tea catechins inhibit growth, proliferation, migration and invasion of estrogen receptor (ER)+ and ER- breast cancer cell lines [20-23]. In addition, it has been shown that green tea catechins block the steps of carcinogenesis [24]. Although the molecular mechanisms of the antiproliferative action of green tea catechins have not been delineated, green tea catechins seem to be multitarget agents, modulating multiple signaling pathways [25]. In addition, green tea catechins have been reported to modulate epigenetic processes. Aberrant epigenetic alterations in the genome such as DNA methylation and chromatin remodeling play a significant role in cancer development. Since epigenetic alterations are considered to be more easily reversible compared to genetic changes, epigenetic therapy is potentially very useful in reversing some of these defects. Indeed, epigenetic processes have been recognized as a new target for anticancer drug design. This review aims to synthesize evidence on the modulation of DNA methylation by green tea catechins.

\section{Methods}

PubMed, Scopus, Google Scholar and Science Citation Index were searched with the search terms 'EGCG', 'green tea catechins', 'breast cancer', 'DNA methylation', 'promoter hypermethylation', 'global DNA hypomethylation', 'epigenomics' and 'epigenetics'. The search covered the period from 1966 up to and including February 2013. Trials that provided evidence on the effect of green tea catechins on the modulation of epigenomic processes met the inclusion criteria. Only full publications were considered. There was no language restriction. The reference list of all identified trials was checked for more relevant articles.

\section{Results}

\section{In silico Data}

Attempting to investigate the mechanism of DNMT1 inhibition at the molecular level, computational modeling analyses have been conducted to probe the interac- tions between EGCG and human DNMT1 [26-28]. A homology model of the human DNMT1 has been used to model the three-dimensional structure of the DNMT1 catalytic domain. Based on molecular modelling, it has been suggested that EGCG shows competitive inhibition of DNMT1 by effectively forming at least four hydrogen bonds within the DNMT1 catalytic binding center, thus blocking the entry of the DNA nucleotide cytosine into its active site and preventing the methylation process [26-28].

\section{Experimental Trials}

Wong et al. [29] reported that EGCG, at physiologically relevant concentrations in vitro, inhibited DNMT and induced the transcription factor Foxp3. In addition, it was shown that in the in vitro culture system, EGCG also reduced the gene expression of all three DNMTs (DNMT 1, DNMT3a and DNMT3b), which correlated with reduced DNA methylation in the Jurkat T cells treated with EGCG [29].

Nandakumar et al. [30] showed that green tea catechins decreased global DNA methylation levels in human epidermoid carcinoma A431 cells in a dose-dependent manner. In addition, EGCG decreased DNMT activity, messenger RNA (mRNA) and protein levels of DNMT1, DNMT3a and DNMT3b and resulted in reexpression of messenger RNAs (mRNAs) and protein expressions of tumor suppressor genes ( $p 16^{I N K 4 a}$ and Cip1/p21) [30]. Treatment of human esophageal KYSE 510 cells with 5-50 $\mu \mathrm{mol} / \mathrm{l}$ of EGCG for 12-144 h has been shown to lower DNMT1 activity leading to concentration- and time-dependent reversal of hypermethylation and reexpression of genes including the tumor suppressor $p 16^{I N K 4 a}, R A R \beta$ (retinoic acid receptor- $\beta$ ), MGMT $\left(\mathrm{O}^{6}-\right.$ methylguanine methyltransferase) and the DNA mismatch repair gene $h M L H 1$ (human mutL homologue 1) [10]. Reactivation of some methylation-silenced genes by EGCG has also been demonstrated in human colon cancer HT-29 cells, esophageal cancer KYSE 150 cells and prostate cancer PC3 cells [26, 27]. Berner et al. [31] have shown that EGCG treatment suppressed promoter methylation of tumor suppressor genes $\mathrm{p} 15^{\mathrm{INK} 4 \mathrm{~b}}$ and $\mathrm{p} 16^{\mathrm{INK} 4 \mathrm{a}}$ in Caco 2 cells [31]. Gao et al. [32] have demonstrated that EGCG reverses promoter methylation of tumor suppressor WIF-1 and restores WIF-1 expression in H460 and A549 lung cancer cells [32]. Gu et al. [33] have shown that EGCG induces apoptosis in renal carcinoma cells possibly through promoter demethylation of tissue factor pathway inhibitor-2, a member of the Kunitz-type serine proteinase inhibitor family, which is inversely related to 
an increasing degree of malignancy [33]. Kato et al. [34] have shown that EGCG partially reversed the hypermethylation status of the tumor suppressor gene RECK and significantly enhanced the expression level of RECK mRNA in oral squamous cell carcinoma cells [34].

Although hypermethylation of gene promoters is generally associated with gene silencing, there are exceptions to this rule such as the $h$ TERT (human telomerase reverse transcriptase), a promoter that, paradoxically, is highly methylated in most tumor cell types, rendering $h T E R T$ active. Treatment with EGCG can also inhibit oncogene expression through influencing the DNA methylation status of these genes. Meeran et al. [35] have shown that treatment with EGCG inhibited the transcription of the tumor-promoting gene $h T E R T$, the catalytic subunit of telomerase, through epigenetic mechanisms in ER+ MCF-7 and ER- MDA-MB-231 cells. The downregulation of hTERT expression was due partly to hTERT promoter hypomethylation mediated through inhibition of DNMT [35]. Mittal et al. [36] have demonstrated that green tea catechins induce apoptosis in MCF-7 breast cancer cells through downregulation of telomerase. They have shown that treatment of MCF-7 cells with EGCG dose-dependently inhibited telomerase activity, and also inhibited the mRNA expression of hTERT. The same investigators also demonstrated that EGCG also inhibited the protein expression of hTERT, which indicated that inhibition of telomerase was associated with downregulation of hTERT [36]. Belretch et al. [37] reported that treatment of MCF-7 cells with EGCG resulted in decreased hTERT mRNA expression. Furthermore, downregulation of hTERT gene expression in MCF-7 cells appeared to be largely due to epigenetic alterations, as evidenced by the time-dependent decrease in hTERT promoter methylation [37].

Lee et al. [28] have reported the in vitro inhibition of DNMT3a and DNMT3b by tea polyphenols using the prokaryotic SssI DNMT. The same investigators have demonstrated the enzymatic inhibition of human DNMT1 by catechin, epicatechin and EGCG [28]. In addition, in the same study, they investigated the effects of EGCG and catechin on the methylation status of the $R A R \beta$ gene in the human breast cancer cell lines MCF-7 and MDA-MB-231. The $R A R \beta$ gene promoter region is hypermethylated in these cells. MCF-7 and MDAMB-231 cells were treated with $0,0.2,1,5,25$, or $50 \mu \mathrm{mol} / 1$ EGCG for 3 or 6 days, respectively, depending on the rate of cell growth. It was shown that EGCG or catechin partially inhibited the methylation status of the promoter regions of the RAR $\beta$ gene [28].

Targeting DNA Methylation with Green Tea Catechins
In a very interesting study, Meeran et al. [38] investigated the possibility of reactivation of ERs in ER- breast cancer cells through treatment with green tea polyphenols. The investigators observed that treatment of ERabreast cancer cells with green tea polyphenols led to the reactivation of ERa expression. The reactivation of ERa expression was consistently correlated with $E R \alpha$ promoter hypomethylation and hyperacetylation [38].

Pandey et al. [39] have investigated the effects of green tea polyphenols on glutathione- $S$-transferase $p i$ (GSTP1) reexpression in human prostate cells. Exposure of human prostate cancer $\mathrm{LNCaP}$ cells to $1-10 \mu \mathrm{g} / \mathrm{ml}$ of green tea polyphenols for 1-7 days caused a concentration- and time-dependent reexpression of GSTP1 which correlated with DNMT1 inhibition. Methyl-specific PCR and sequencing revealed extensive demethylation in the proximal GSTP1 promoter and regions distal to the transcription factor binding sites. In addition, green tea polyphenol exposure resulted in a decrease in DNMT1 protein expression. Cells treated with varying doses of green tea polyphenols for 3 days resulted in a dose-dependent 0.5 to 0.85 -fold decrease in the levels of mRNA of DNMT1 [39].

A very recently published trial suggests that green tea catechins inhibit DNA methylation targeting ubiquitinlike containing PHD and Ring finger 1 (UHRF1) that contribute to silencing of tumor suppressor genes by recruiting DNMT1 to their hemi-methylated promoters. The investigators showed that EGCG downregulates UHRF1 and DNMT1 expression in Jurkat cells, with subsequent upregulation of the $\mathrm{p} 73$ and $\mathrm{p} 16^{\mathrm{INK} 4 \mathrm{~A}}$ genes. The downregulation of UHRF1 was dependent upon the generation of reactive oxygen species by EGCG. Upregulation of $\mathrm{p} 16^{\mathrm{INK} 4 \mathrm{~A}}$ was strongly correlated with decreased promoter binding by UHRF1. UHRF1 overexpression counteracted EGCG-induced G1-arrested cells, apoptosis and upregulation of $\mathrm{p} 16^{\mathrm{INK} 4 \mathrm{~A}}$ and $\mathrm{p} 73$. The investigators concluded that downregulation of UHRF1 is upstream to many cellular events, including G1 cell arrest, upregulation of tumor suppressor genes and apoptosis [40].

\section{Discussion}

Green tea catechins seem to be promising multitarget agents in cancer chemoprevention and adjuvant and metastatic treatment of cancer as they are natural compounds with a rather acceptable safety profile targeting multiple signaling pathways. Furthermore, green tea catechins

Pharmacology 2015;95:111-116 
Table 1. Experimental studies suggesting modulation of DNA methylation by green tea catechins

\begin{tabular}{|c|c|c|c|}
\hline Authors & Experimental model & Main finding & Suggested mechanism \\
\hline Meeran et al. [38] & $\begin{array}{l}\text { MDA-MB-453 (ER-) and } \\
\text { MDA-MB-231 (ER-) cells }\end{array}$ & $\begin{array}{l}\text { green tea polyphenols led to the reactivation } \\
\text { of ERa expression partly via } E R \alpha \text { promoter } \\
\text { hypomethylation }\end{array}$ & $\begin{array}{l}\text { inhibition of DNMTs } \\
\text { activity and expression }\end{array}$ \\
\hline Wong et al. [29] & Jurkat T cells & $\begin{array}{l}\text { EGCG at physiologically relevant } \\
\text { concentrations inhibited DNMT }\end{array}$ & $\begin{array}{l}\text { reduction of the gene } \\
\text { expression of all three } \\
\text { DNMTs }\end{array}$ \\
\hline $\begin{array}{l}\text { Nandakumar et al. } \\
\text { [30] }\end{array}$ & $\begin{array}{l}\text { human epidermoid carcinoma } \\
\text { cell line A } 431\end{array}$ & $\begin{array}{l}\text { EGCG reduced the levels of DNA } \\
\text { methylation and DNMT activity }\end{array}$ & $\begin{array}{l}\text { reduction of the gene } \\
\text { expression of all three } \\
\text { DNMTs }\end{array}$ \\
\hline Meeran et al. [35] & $\begin{array}{l}\text { ER+ MCF-7 and ER- } \\
\text { MDA-MB-231 cells }\end{array}$ & $\begin{array}{l}\text { EGCG inhibited the transcription of the } \\
\text { tumor-promoting gene } h T E R T\end{array}$ & $\begin{array}{l}\text { downregulation of hTERT } \\
\text { expression partly due to } \\
\text { hTERT promoter } \\
\text { hypomethylation }\end{array}$ \\
\hline Berner et al. [31] & Caco 2 cells & $\begin{array}{l}\text { EGCG treatment suppressed promoter } \\
\text { methylation of tumor suppressor genes }\end{array}$ & not investigated \\
\hline Pandey et al. [39] & $\begin{array}{l}\text { human prostate cancer LNCaP } \\
\text { cells }\end{array}$ & $\begin{array}{l}\text { treatment with green tea polyphenols caused } \\
\text { a reexpression of GSTP1 }\end{array}$ & $\begin{array}{l}\text { inhibition of DNMT1 } \\
\text { protein expression }\end{array}$ \\
\hline Kato et al. [34] & $\begin{array}{l}\text { oral squamous cell carcinoma } \\
\text { cells }\end{array}$ & $\begin{array}{l}\text { EGCG partially reversed the } \\
\text { hypermethylation status of the tumor } \\
\text { suppressor gene RECK }\end{array}$ & not investigated \\
\hline Berletch et al. [37] & MCF-7 cells & $\begin{array}{l}\text { treatment of MCF- } 7 \text { cells with EGCG } \\
\text { resulted in decreased hTERT mRNA } \\
\text { expression }\end{array}$ & not further investigated \\
\hline Gao et al. [32] & H460 and A549 lung cancer cells & $\begin{array}{l}\text { EGCG reversed promoter methylation of } \\
\text { tumor suppressor WIF-1 }\end{array}$ & not investigated \\
\hline Gu et al. [33] & renal carcinoma cells & $\begin{array}{l}\text { EGCG induces apoptosis possibly via } \\
\text { promoter demethylation }\end{array}$ & not investigated \\
\hline Lee et al. [28] & $\begin{array}{l}\text { in vitro enzymatic inhibition of } \\
\text { DNMT using recombinant } \\
\text { prokaryotic SssI DNMT and } \\
\text { human DNMT1 as model } \\
\text { enzymes }\end{array}$ & $\begin{array}{l}\text { EGCG inhibited SssI DNMT- and } \\
\text { DNMT1-mediated DNA methylation }\end{array}$ & $\begin{array}{l}\text { direct inhibition of the } \\
\text { DNMTs and indirect } \\
\text { inhibition of the enzyme }\end{array}$ \\
\hline Mittal et al. [36] & MCF-7 cells & $\begin{array}{l}\text { treatment of MCF- } 7 \text { cells with EGCG } \\
\text { inhibited telomerase activity and mRNA } \\
\text { expression of hTERT }\end{array}$ & $\begin{array}{l}\text { epigenetic regulation of } \\
\text { hTERT }\end{array}$ \\
\hline Fang et al. [27] & $\begin{array}{l}\text { esophageal KYSE } 510 \text { cells, } \\
\text { human colon cancer HT-29 } \\
\text { cells, esophageal cancer KYSE } \\
150 \text { cells, and prostate cancer } \\
\text { PC } 3 \text { cells }\end{array}$ & $\begin{array}{l}\text { reversal of hypermethylation of p16(INK4a), } \\
\text { RAR } \beta \text {, MGMT, and hMLH1 genes; } \\
\text { reactivation of some methylation-silenced } \\
\text { genes by EGCG }\end{array}$ & $\begin{array}{l}\text { enzymatic inhibition of } \\
\text { DNMT by EGCG }\end{array}$ \\
\hline
\end{tabular}

have been shown to reduce cell proliferation through modulation of cell cycle progression and through induction of apoptosis of cancer cells. Epigenetic modulation seems to be upstream of many cellular events including G1 cell arrest, upregulation of tumor suppressor genes and apoptosis [40]. Finally, redox regulation might be upstream of epigenetic modulation. Green tea catechins also modulate redox regulation. Thus, green tea catechins could be promising multitarget chemopreventive and chemotherapeutic agents. Especially modulation of DNA 
methylation by green tea catechins could lead to the upregulation of tumor suppressor genes and the downregulation of oncogenes.

Experimental evidence suggests that green tea catechins and especially EGCG modulate DNA methylation by attenuating the effect of DNMT1 (table 1). However, the exact mechanism of DNMT1 inhibition is not delineated. Suggested mechanisms include direct enzymatic inhibition, indirect enzymatic inhibition, reduced DNMT1 expression and translation. Data based on in vitro assays suggest enzymatic inhibition of DNMT3a and DNMT3b by green tea catechins. However, the biological effect of this inhibition has not been investigated. In addition, the possible effect of green tea catechins on other pathways of DNA methylation, i.e. methyl-CpG binding domain proteins has not been investigated. Furthermore, the link between redox properties and epigenetic modulation by green tea catechins has not been defined either; is modulation of redox properties upstream of modulation of DNA methylation?

In addition, an interesting question is if there are any possible negative effects of modulation of DNA methylation by green tea catechins. Although inhibition of DNMT is expected to prevent hypermethylation, severe inhibition of DNMT activity, as suggested by recent genetic studies, may cause DNA hypomethylation, genomic instability and early development of cancers such as T-cell lymphomas and sarcomas. Recently, several inactivating mutations of de novo DNMTs in various types of tumor have been identified. In addition, it has been shown that loss of de novo DNA methylation activity at advanced tumor stages leads to the promoter DNA demethylationdependent expression of specific oncogenes. These data suggest that de novo DNMTs also have an important role in the maintenance of DNA methylation and that, in addition to acting as oncogenes, they also behave as tumor suppressors $[41,42]$.

In conclusion, experimental evidence indicates that green tea catechins modulate DNA methylation. However, the exact mechanisms that underlie the inhibition of DNA methylation by green tea catechins are not clearly defined. Since green tea catechins are natural compounds with a rather acceptable safety profile, further research on their action as inhibitors of DNA methylation seems worthwhile.

\section{References}

1 Chomet PS: Cytosine methylation in genesilencing mechanisms. Curr Opin Cell Biol 1991;3:438-434.

2 Fukushige S, Horii A: DNA methylation in cancer: a gene silencing mechanism and the clinical potential of its biomarkers. Tohoku J Exp Med 2013;229:173-185.

3 Jones PA, Laird PW: Cancer epigenetics comes of age. Nat Genet 1999;21:163-167.

4 Jones PA, Baylin SB: The fundamental role of epigenetic events in cancer. Nat Rev Genet 2002:3:415-428.

5 Bogdanović O, Veenstra GJ: DNA methylation and methyl-CpG binding proteins: developmental requirements and function. Chromosoma 2009;118:549-565.

6 Ballestar E, Esteller M: Methyl-CpG-binding proteins in cancer: blaming the DNA methylation messenger. Biochem Cell Biol 2005; 83:374-384.

7 Worm J, Guldberg P: DNA methylation: an epigenetic pathway to cancer and a promising target for anticancer therapy. J Oral Pathol Med 2002;31:443-449.

8 Okano M, Bell DW, Haber DA, Li E: DNA methyltransferases Dnmt3a and Dnmt3b are essential for de novo methylation and mammalian development. Cell 1999;99:247-245.
9 Okano M, Xie S, Li E: Cloning and characterization of a family of novel mammalian DNA (cytosine-5) methyltransferases. Nat Genet 1998; 19:219-220.

10 Bestor T: The DNA methyltransferases of mammals. Hum Mol Genet 2000;9:23952402.

11 Figueiredo JC, Grau MV, Wallace K, Levine AJ, Shen L, Hamdan R, Chen X, Bresalier RS, McKeown-Eyssen G, Haile RW, Baron JA, Issa JP: Global DNA hypomethylation (LINE-1) in the normal colon and lifestyle characteristics and dietary and genetic factors. Cancer Epidemiol Biomarkers Prev 2009;18:1041-1049.

12 Cabrera C, Artacho R, Gimenez R: Beneficial effects of green tea: a review. J Am Coll Nutr 2006;25:79-99.

13 McKay DL, Blumberg JB: The role of tea in human health: an update. J Am Coll Nutr 2002;21:1-13.

14 Nihal M, Ahmad N, Mukhtar H, Wood GS: Anti-proliferative and proapoptotic effects of (-)-epigallocatechin-3-gallate on human melanoma: possible implications for the chemoprevention of melanoma. Int J Cancer 2005;114:513-521.

15 Khan N, Mukhtar H: Modulation of signaling pathways in prostate cancer by green tea polyphenols. Biochem Pharmacol 2013;85:667672.
16 Bailey $\mathrm{HH}$, Mukhtar H: Green tea polyphenols and cancer chemoprevention of genitourinary cancer. Am Soc Clin Oncol Educ Book 2013;2013:92-96.

17 Zhou DH, Wang X, Yang M, Shi X, Huang W, Feng Q: Combination of low concentration of (-)-epigallocatechin gallate (EGCG) and curcumin strongly suppresses the growth of nonsmall cell lung cancer in vitro and in vivo through causing cell cycle arrest. Int J Mol Sci 2013;14:12023-12036.

18 Stingl JC, Ettrich T, Muche R, Wiedom M, Brockmöller J, Seeringer A, Seufferlein T: Protocol for minimizing the risk of metachronous adenomas of the colorectum with green tea extract (MIRACLE): a randomised controlled trial of green tea extract versus placebo for nutriprevention of metachronous colon adenomas in the elderly population. BMC Cancer 2011;11:360.

19 Shimizu M, Sakai H, Shirakami Y, Yasuda Y, Kubota M, Terakura D, Baba A, Ohno T, Hara Y, Tanaka T, Moriwaki H: Preventive effects of (-)-epigallocatechin gallate on diethylnitrosamine-induced liver tumorigenesis in obese and diabetic C57BL/KsJ-db/db mice. Cancer Prev Res (Phila) 2011;4:396-403. 
20 Alshatwi AA: Catechin hydrate suppresses MCF-7 proliferation through TP53/caspasemediated apoptosis. J Exp Clin Cancer Res 2010;29:167.

21 Hsuuw YD, Chan WH: Epigallocatechin gallate dose-dependently induces apoptosis or necrosis in human MCF-7 cells. Ann NY Acad Sci 2007;1095:428-440.

22 Zhao X, Tian H, Ma X, Li L: Epigallocatechin gallate, the main ingredient of green tea induces apoptosis in breast cancer cells. Front Biosci 2006;11:2428-2433.

23 Thangapazham RL, Singh AK, Sharma A, Warren J, Gaddipati JP, Maheshwari RK: Green tea polyphenols and its constituent epigallocatechin gallate inhibits proliferation of human breast cancer cells in vitro and in vivo. Cancer Lett 2007;245:232-241.

24 Sakata M, Ikeda T, Imoto S, Jinno H, Kitagawa $Y$ : Prevention of mammary carcinogenesis in $\mathrm{C} 3 \mathrm{H} / \mathrm{OuJ}$ mice by green tea and tamoxifen. Asian Pac J Cancer Prev 2011;12:567-571.

25 Beltz LA, Bayer DK, Moss AL, Simet IM: Mechanisms of cancer prevention by green and black tea polyphenols. Anticancer Agents Med Chem 2006;6:389-406.

26 Fang M, Chen D, Yang CS: Dietary polyphenols may affect DNA methylation. J Nutr 2007;137(suppl 1):223S-228S.

27 Fang MZ, Wang Y, Ai N, Hou Z, Sun Y, Lu H, Welsh W, Yang CS: Tea polyphenol (-)-epigallocatechin-3-gallate inhibits DNA methyltransferase and reactivates methylation-silenced genes in cancer cell lines. Cancer Res 2003;63:7563-7567.

28 Lee WJ, Shim JY, Zhu BT: Mechanisms for the inhibition of DNA methyltransferases by tea catechins and bioflavonoids. Mol Pharmacol 2005;68:1018-1030.
29 Wong CP, Nguyen LP, Noh SK, Bray TM, Bruno RS, Ho E: Induction of regulatory T cells by green tea polyphenol EGCG. Immunol Lett 2011;139:7-13.

30 Nandakumar V, Vaid M, Katiyar SK: (-)-Epigallocatechin-3-gallate reactivates silenced tumor suppressor genes, Cip1/p21 and p16INK4a, by reducing DNA methylation and increasing histones acetylation in human skin cancer cells. Carcinogenesis 2011;32: 537-544.

31 Berner C, Aumüller E, Gnauck A, Nestelberger M, Just A, Haslberger AG: Epigenetic control of estrogen receptor expression and tumor suppressor genes is modulated by bioactive food compounds. Ann Nutr Metab 2010; 57:183-189.

32 Gao Z, Xu Z, Hung MS, Lin YC, Wang T, Gong M, Zhi X, Jablon DM, You L: Promoter demethylation of WIF-1 by epigallocatechin3 -gallate in lung cancer cells. Anticancer Res 2009;29:2025-2030.

33 Gu B, Ding Q, Xia G, Fang Z: EGCG inhibits growth and induces apoptosis in renal cell carcinoma through TFPI-2 overexpression. Oncol Rep 2009;21:635-640.

34 Kato K, Long NK, Makita H, Toida M, Yamashita T, Hatakeyama D, Hara A, Mori H, Shibata T: Effects of green tea polyphenol on methylation status of RECK gene and cancer cell invasion in oral squamous cell carcinoma cells. Br J Cancer 2008;99:647-645.

35 Meeran SM, Patel SN, Chan TH, Tollefsbol TO: A novel prodrug of epigallocatechin3-gallate: differential epigenetic hTERT repression in human breast cancer cells. Cancer Prev Res (Phila) 2011;4:1243-1254.
36 Mittal A, Pate MS, Wylie RC, Tollefsbol TO, Katiyar SK: EGCG down-regulates telomerase in human breast carcinoma MCF-7 cells, leading to suppression of cell viability and induction of apoptosis. Int J Oncol 2004;24: 703-710.

37 Berletch JB, Liu C, Love WK, Andrews LG, Katiyar SK, Tollefsbol TO: Epigenetic and genetic mechanisms contribute to telomerase inhibition by EGCG. J Cell Biochem 2008; 103:509-519.

38 Meeran SM, Patel SN, Li Y, Shukla S, Tollefsbol TO: Bioactive dietary supplements reactivate ER expression in ER-negative breast cancer cells by active chromatin modifications. PLoS One 2012;7:e37748.

39 Pandey M, Shukla S, Gupta S: Promoter demethylation and chromatin remodeling by green tea polyphenols leads to re-expression of GSTP1 in human prostate cancer cells. Int J Cancer 2010;126:2520-2523.

40 Achour M, Mousli M, Alhosin M, Ibrahim A, Peluso J, Muller CD, Schini-Kerth VB, Hamiche A, Dhe-Paganon S, Bronner C: Epigallocatechin-3-gallate up-regulates tumor suppressor gene expression via a reactive oxygen species-dependent down-regulation of UHRF1. Biochem Biophys Res Commun 2013;430:208-212.

41 Eden A, Gaudet F, Waghmare A, Jaenisch R: Chromosomal instability and tumors promoted by DNA hypomethylation. Science 2003;300:455.

42 Gaudet F, Hodgson JG, Eden A, JacksonGrusby L, Dausman J, Gray JW, Leonhardt H, Jaenisch R: Induction of tumors in mice by genomic hypomethylation. Science 2003;300: 489-492. 